Supplement of The Cryosphere, 12, 685-699, 2018 https://doi.org/10.5194/tc-12-685-2018-supplement (C) Author(s) 2018. This work is distributed under the Creative Commons Attribution 4.0 License.

(c) (1)

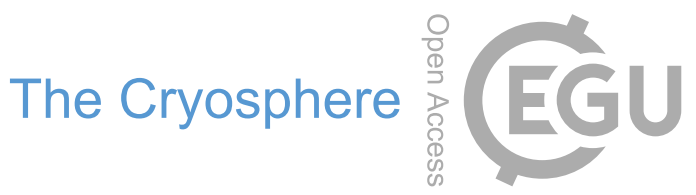

Supplement of

\title{
Floe-size distributions in laboratory ice broken by waves
}

Agnieszka Herman et al.

Correspondence to: Agnieszka Herman (oceagah@ug.edu.pl)

The copyright of individual parts of the supplement might differ from the CC BY 4.0 License. 


\section{Wave attenuation in Test Group A and B}

Note different horizontal scales in Suppl. Fig. 1 and 2.

Test A, run 2010

Test A, run 2020
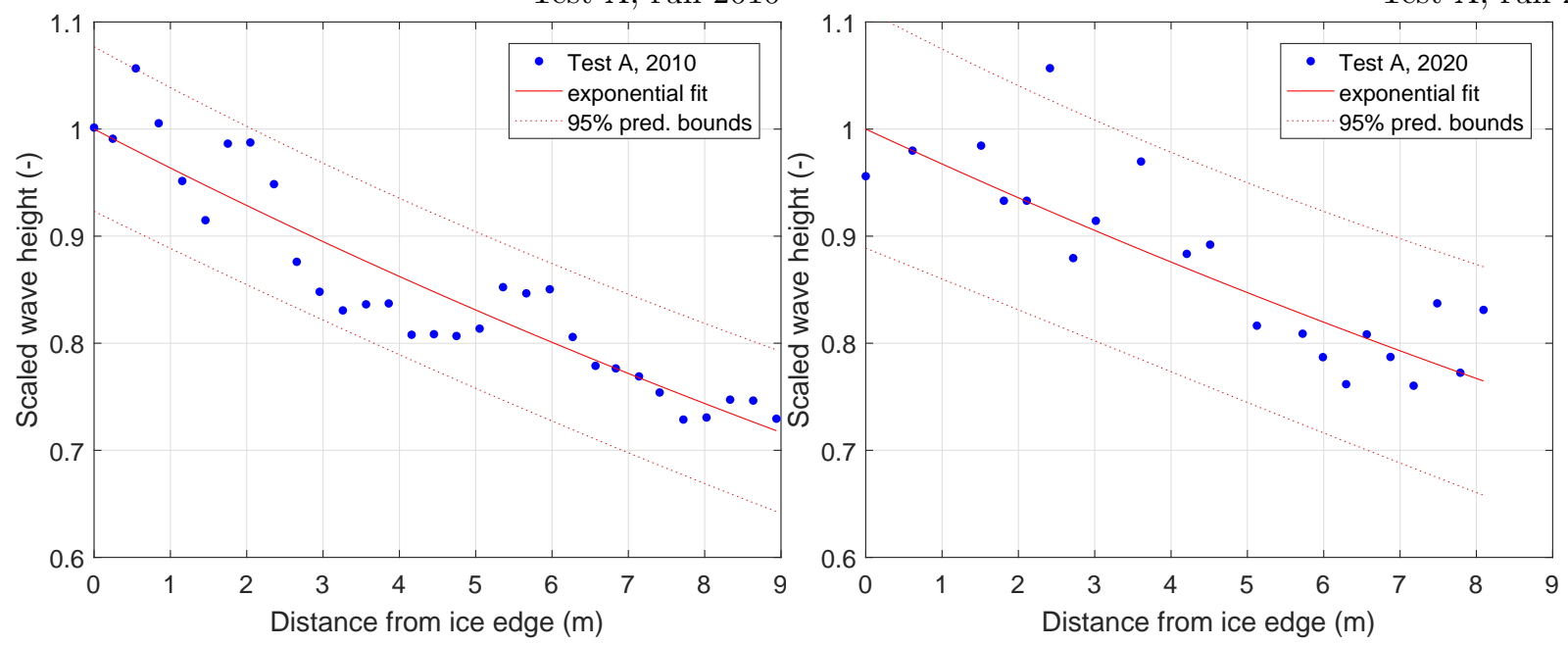

Supplementary Figure 1: Normalized wave height $\left(\bar{H}=H / H_{0}\right)$ in function of the distance from the ice edge, $x$, in two selected test runs from Group A, 2010 and 2020. Values estimated from the Qualisys data. Red line shows the best fit of an exponential function $\bar{H}=\exp \left(-\alpha_{a} x\right)$, with $\alpha_{a}=(3.70 \pm 0.57) \cdot 10^{-2} \mathrm{~m}^{-1}$ in test 2010 and $\alpha_{a}=(3.31 \pm 1.03) \cdot 10^{-2} \mathrm{~m}^{-1}$ in test 2020.
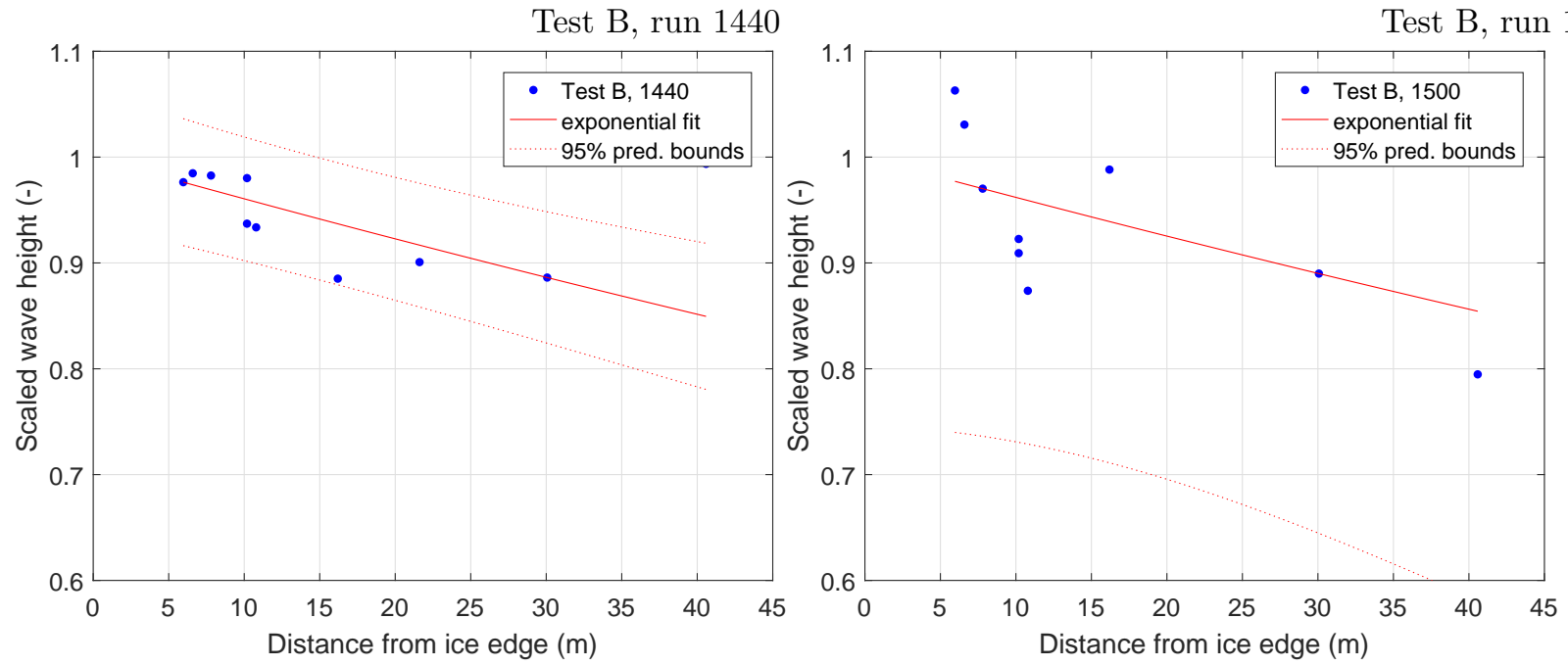

Supplementary Figure 2: Normalized wave height $\left(\bar{H}=H / H_{0}\right)$ in function of the distance from the ice edge, $x$, in two selected test runs from Group B, 1440 and 1500. Values estimated from the pressure and ultrasound sensor data. Red line shows the best fit of an exponential function $\bar{H}=\exp \left(-\alpha_{a} x\right)$, with $\alpha_{a}=(0.40 \pm 0.18) \cdot 10^{-2} \mathrm{~m}^{-1}$ in test 1440 and $\alpha_{a}=(0.39 \pm 0.71) \cdot 10^{-2} \mathrm{~m}^{-1}$ in test 1500 . 


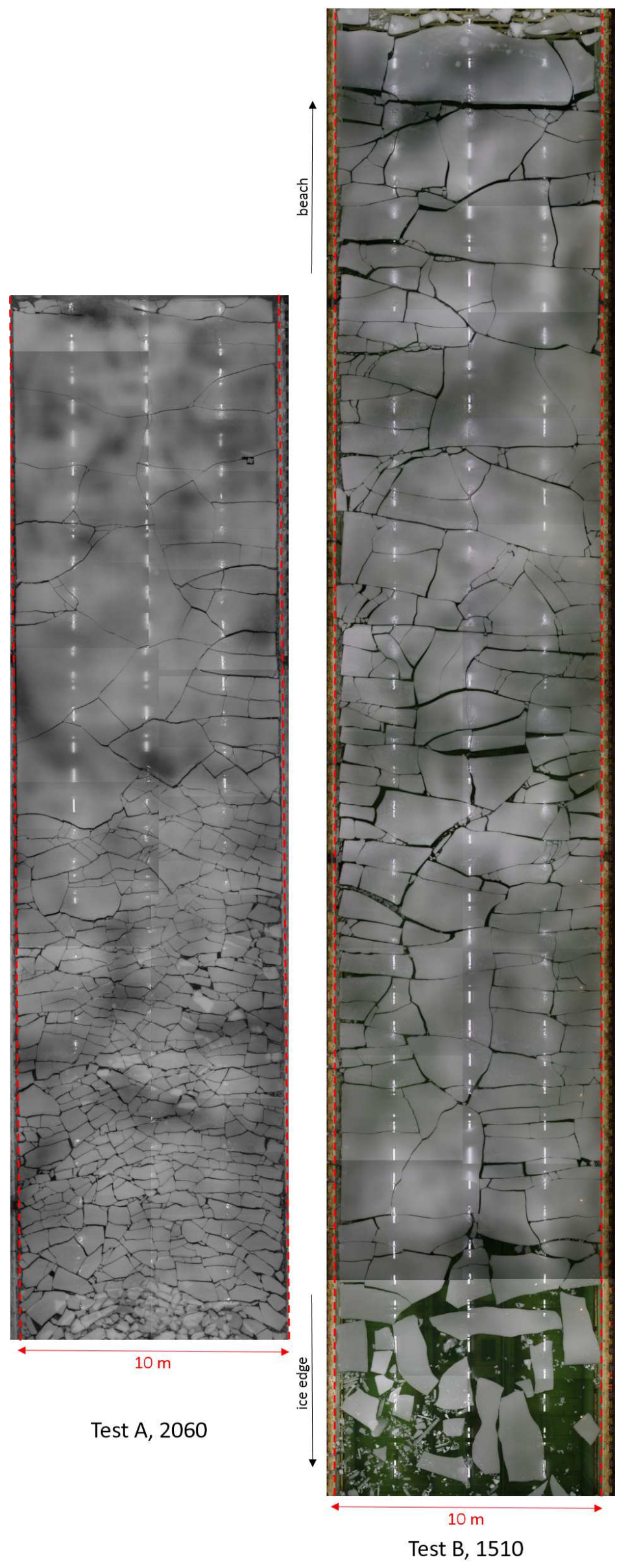

Supplementary Figure 3: Stitched images of the ice tank (composed of individual photographs from the crane camera) after test 2060 and 1510. 


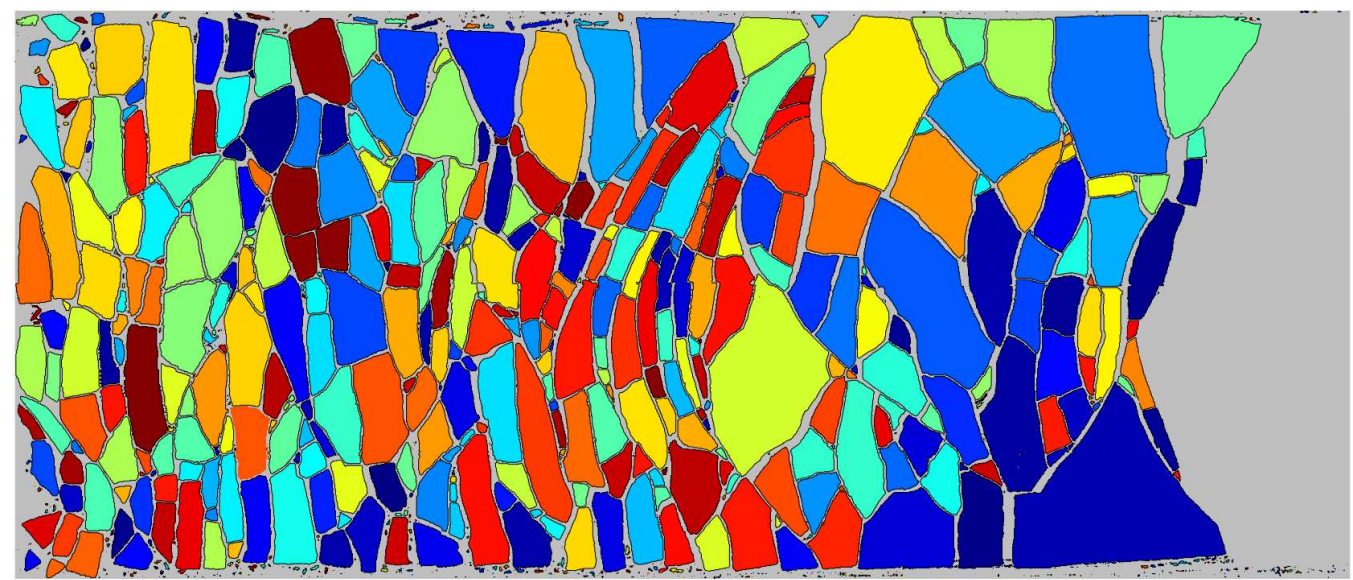

Test A, run 2030

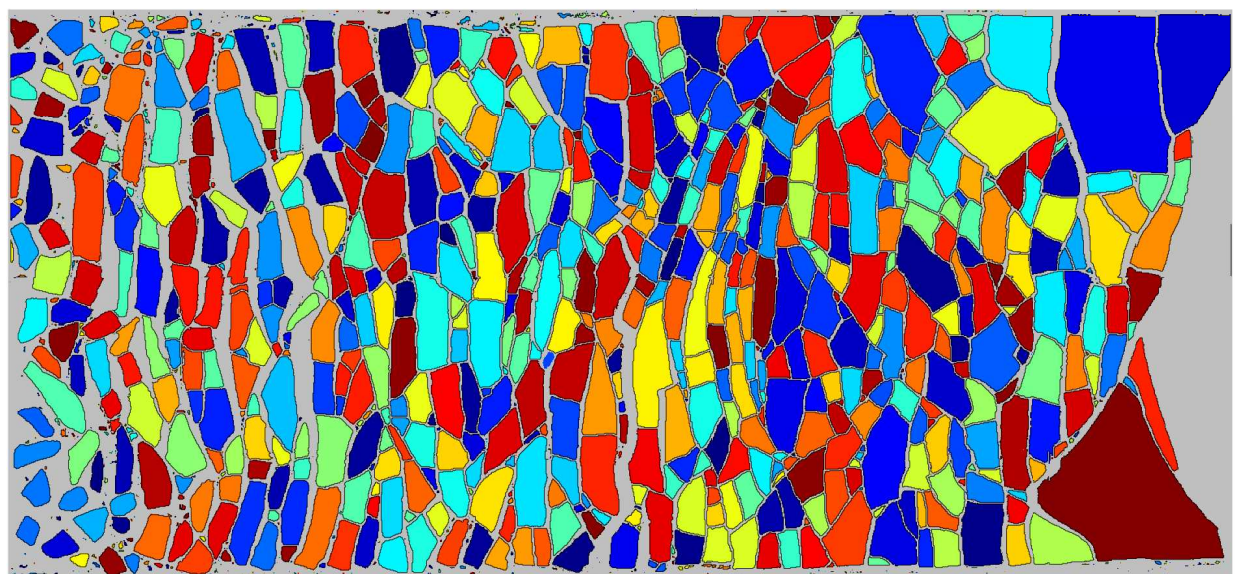

Test A, run 2060 (subset)

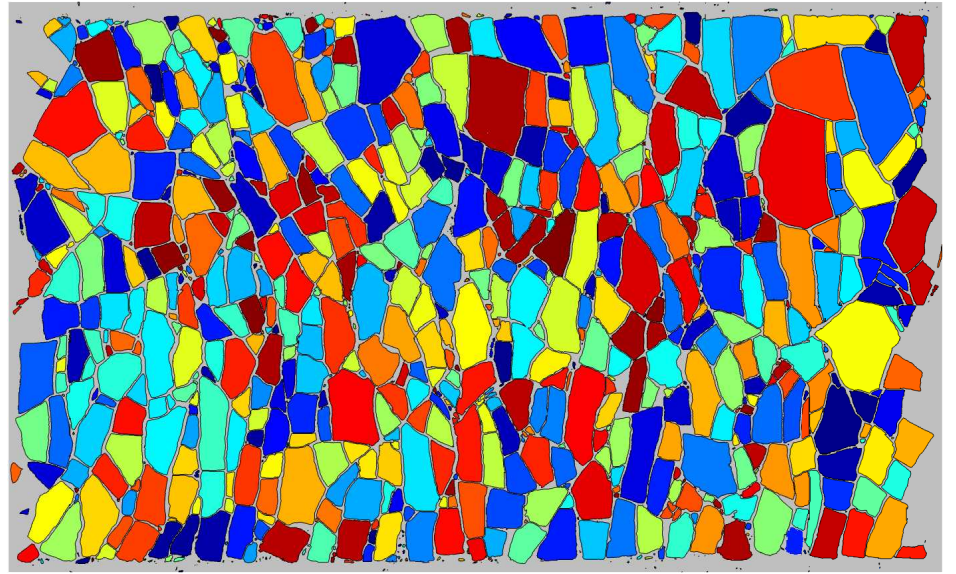

Test A, run 2060 (whole)

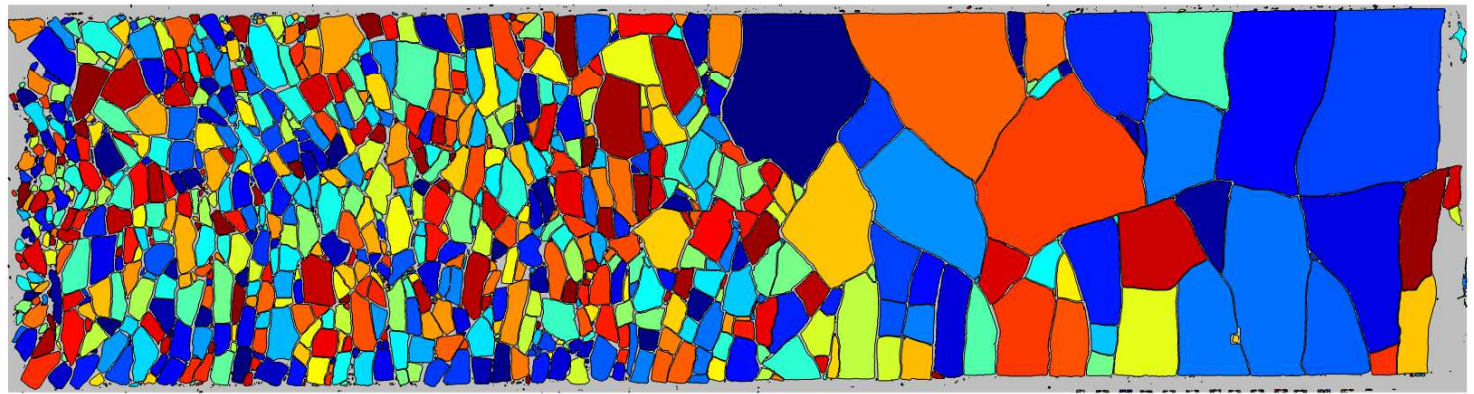

Supplementary Figure 4: Final result of the image analysis from Test Group A, with identified ice floes marked by black contours and randomly selected colors. The ice edge is to the left, the beach to the right; the height of the image corresponds to the distance of $10 \mathrm{~m}$ (tank width), gray areas are open water or ice that could not be identified (very small pieces, unbroken ice sheet, etc.). 
Test B, run 1450 (subset)

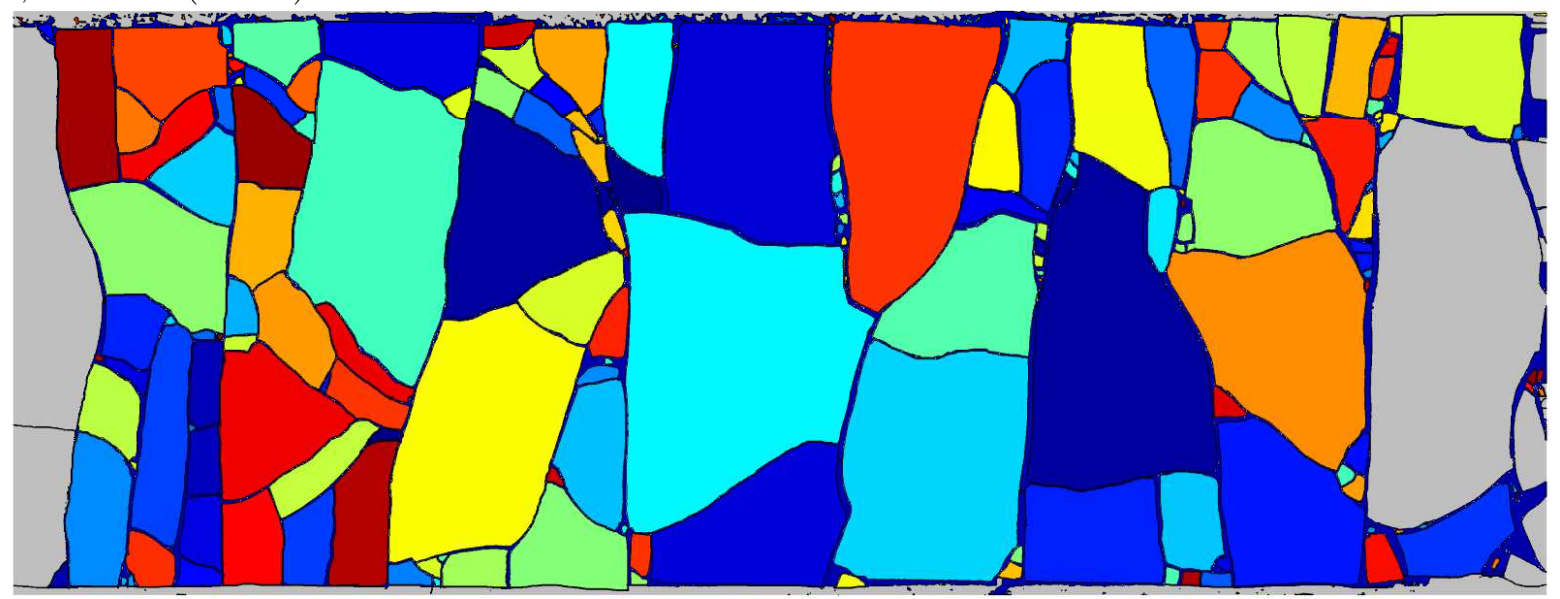

Test B, run 1450 (whole)

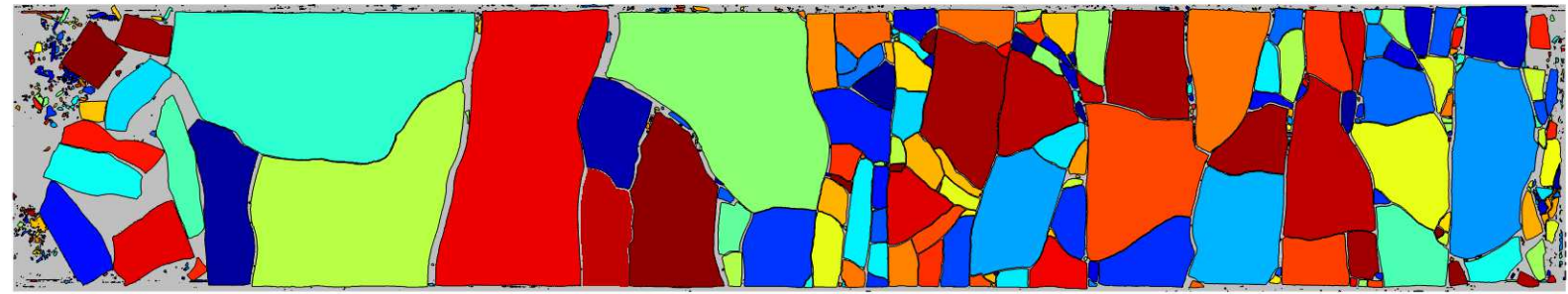

Test B, run 1510

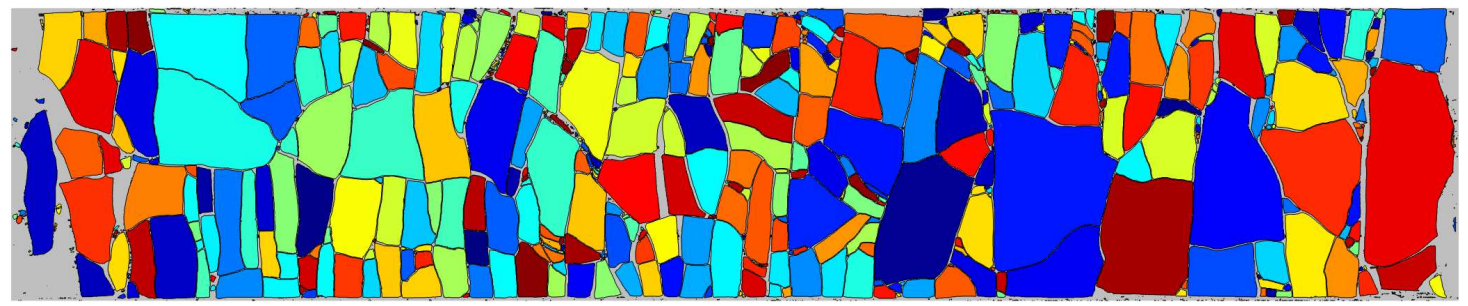

Supplementary Figure 5: As in Supplementary Fig. 4, but for the Test Group B.

(a)

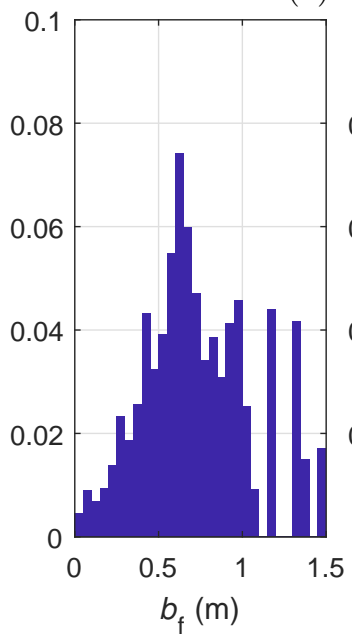

(b)

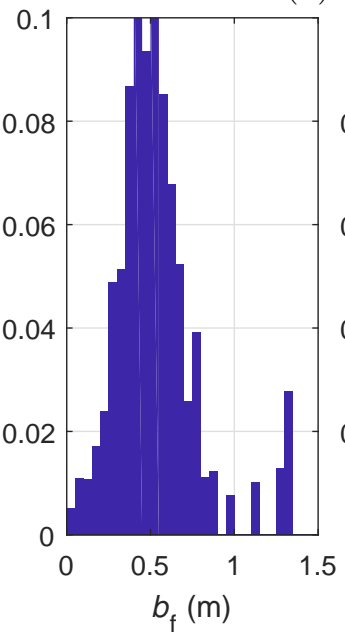

(c)

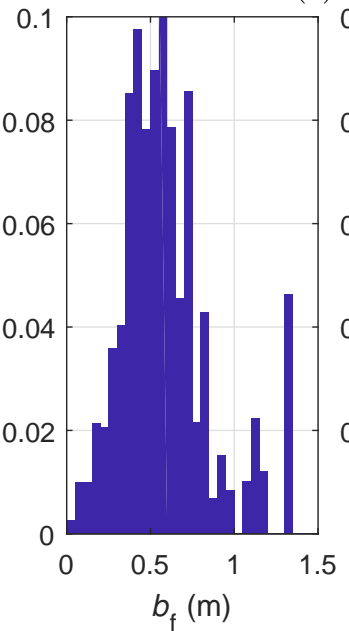

(c)

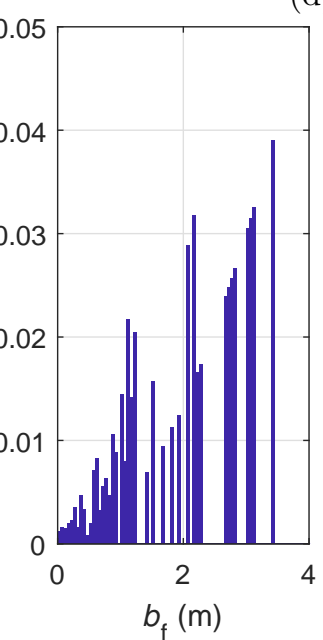

(d)

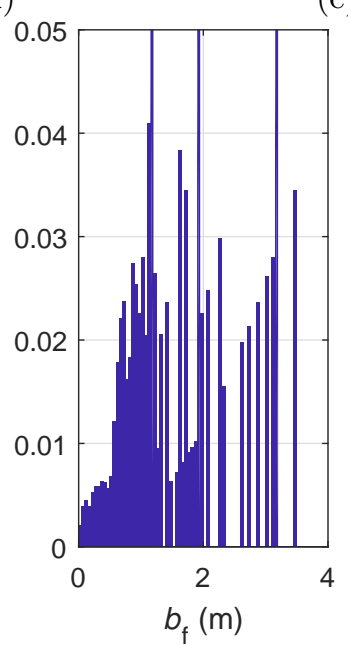

Supplementary Figure 6: Histograms, analogous to those in Fig. 5a-e in the main text, of area-weighted floe-size distributions from Test Group A and B. Note that, although the bin width is the same in all cases, the $x$-axis limits are different in $\mathrm{a}-\mathrm{c}$ and $\mathrm{d}, \mathrm{e}$. 